\title{
MIGRANTES O REFUGIADOS: DE LA PATRIA SOLO LA IMAGEN EN SU MENTE
}

\section{Migrants or refugees: from the countryonly the image in your mind}

\section{Migrantes ou refugiados: da pátria apenas a imagem na sua mente}

\author{
Jenny González Muñoz \\ (Universidade de Passo Fundo) \\ Noemí Frías Durán \\ (UPEL) - Instituto Pedagógico de Caracas - Venezuela) \\ Informações do artigo \\ Recebido em 06/05/2019 \\ Aceito em 03/08/2019 \\ doi>: https://doi.org/10.25247/2447-861X.2019.n247.p276-301
}

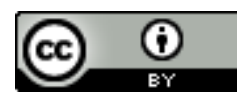

Esta obra está licenciada com uma Licença Creative Commons Atribuição 4.0 Internacional.

Como ser citado (modelo ABNT)

GONZÁLEZ MUÑOZ, Jenny; FRÍAS DURÁN, Noemí. Migrantes o refugiados: de la patria solo la imagen en su mente. Cadernos do CEAS: Revista Crítica de

Humanidades, Salvador, n. 247, mai./ago., p. 276-301, 2019. DOI: https://doi.org/10.25247/2447-

861X.2019.n247.p276-301

\begin{abstract}
Resumem
El presente ensayo es producto de un trabajo realizado en dos etapas temporales y territoriales, con relación a la situación de las migraciones en el mundo y las múltiples aristas que a partir de ellas se desencadenas en diversos análisis hermenéuticos y fenomenológicos. En este sentido, en un primer momento mostramos de manera general la situación de migrantes y refugiados frente a procesos de construcción cultural y sentido de identidad, para luego, en un segundo momento presentar parte de la historia de vida de María Durán, migrante colombiana a tierras venezolanas, durante la tercera década del siglo XX; todo con el objetivo de intentar entender que causas de migracionesysituaciones de refugio puedenser múltiples, como la propia construcción del humano social.
\end{abstract}

Palabras clave: Fenómenos culturales. Identidades. Migraciones. Violencias. Tejidos.

\section{Abstract}

This essay is the product of a work carried out in two temporal and territorial stages in relation to the situation of migrations in the world and the multiple edges that are triggered from them in varioushermene utical and phenomenological analyzes. In this sense, at first we show in a general way the situation of migrants and refugees facing processes of cultural construction and sense of identity, and then, in a second moment, present part of the life story of María Durán, a Colombian migrant Venezuelan lands, during the third decade of the 2oth century; all with the aim of trying to understand that the causes of migrations and situations of refuge can be multiple, such as the very construction of the social human.

Keywords: Cultural processes. Identities. Migrations. Violence. Fabrics.

\section{Resumo}

Este artigo é o produto de um trabalho realizado em dois estágios temporais e territoriais em relação à situação das migrações no mundo e das múltiplas faces que se desenvolvem a partir delas e com ênfase em análises hermenêuticas e fenomenológicas. Nesse sentido, a princípio mostramos de maneira geral a situação dos migrantes e refugiados diante de processos de construção cultural e senso de identidade, e depois, em um segundo momento, apresentamos parte da história de vida de María Durán, uma imigrante colombiana que foi para terras venezuelanas durante a terceira década do século $\mathrm{XX}_{\text {; }}$ tudo com o objetivo de tentar entender que causas das migrações e situações de refúgio podem ser múltiplas, tais a própria construção do humano social.

Palavras-chave: Fenômenos culturais. Identidades. Migrações. Violência. Tecidos. 


\section{Introducción}

El ensayo que estamos presentando en estas líneas está pensado desde la contemporaneidad, pero con visos de un pasado remoto que abarca parte de nuestras memorias como mujeres, luchadoras, profesionales, también a veces amas de casa, madres, hermanas e hijas. Por ello, amparadas en esas memorias que forman parte de nuestra formación humana nos permitimos alejarnos un tanto del camino academicista de normativas que, también nosotras como profesoras hemos utilizado. Solicitamos, entonces, la aquiescencia a lectoras y lectores para hablar en primera persona del plural, desde la experiencia que queremos compartir.

Hablar de refugiados, implica el análisis de una serie de factores que van desde lo meramente familiarhasta lo más álgido del sistema socio-político-económico de un individuo social, lo cual implica el alejarse del lugar originario (bien sea donde se nació o donde se llevó a cabo la mayor parte de su vida) en búsqueda de mejoras sustanciales. Vale la pena, en este punto, detenernos en el concepto develado en la Guía sobre el Derecho Internacional de los Refugiados (2001, p. 9) en la que se expresa que "de conformidad con la Convención de la OUA, de 1951, sobre el Estatuto de los Refugiados, un refugiado es una persona que tiene "fundados temores por ser perseguida" ${ }^{1}$, por diversas razones; más adelante se explica que en el caso específico de africanos se amplía el término expresado en la Convención de 1951, manifestando que un refugiado es aquella persona que debido a agresiones, ocupación, dominios extranjeros, entre otros aspectos de violencia, "se vea obligada a huir del lugar donde habitualmente reside" (p. 9). Siguiendo con el marco histórico la misma guía devela que en 1984 se adopta la Declaración de Cartagena, en la cual se extiende más aún el ámbito de dicha definición, formulando que son quienes "han huido de sus países porque su vida, seguridad o libertad han sido amenazadas por la violencia generalizada, la agresión extranjera, los conflictos internos, la violación masiva de los derechos humanos $u$ otras circunstancias que hayan perturbado gravemente el orden público." (2001, p. 9); de manera tal que partiendo de dichas premisas podemos inferir puntos comunes a la situación del refugiado establecida a partir de su decisión de dejar su lugar natural de hábitat: temor a

${ }^{1}$ Disponible en https://www.acnur.org/fileadmin/Documentos/Publicaciones/2012/8951.pdf Acceso en 15 abril 2019. 
algúntipo de violencia, entendida ésta no necesariamente des de la perspectiva de la agresión física sino también como un proceso que se va construyendo en la parte psicológica de la persona como componente de un grupo social.

En todo este contexto inferimos que una persona que se siente visiblemente perseguida y agredida en su derecho a libre vida, y desde allí toma la decisión de irse de su lugar de convivencia formal para intentar retomarsu paz, al llegaral lugardonde hará posible una nueva ritualización de su existencia social (AUGÉ, 1993) se convierte en un refugiado. Entonces veremos que un refugio puede ser visto como aquel lugar que nos proporciona una protección, lo cual no abarcaría, en el caso más amplio del término, solo personas sino animales en varias de sus especies y motivos para buscar tales espacios y circunstancias, de lo cual no hablaremos en este texto pues se aparta totalmente de nuestro tema de investigación, no obstante, es interesante observar cómo no es potestativo de la raza humana el buscar lugares para su propia protección. Esos espacios, cabe señalar, están caracterizados por la presencia de otros grupos humanos, dando paso así a una nueva construcción cultural con inclusión de crisis identitarias y dificultades de adaptación e integración.

En el presente ensayo abordaremos la situación de la migración internacional, desde la perspectiva de la memoria, los procesos culturales y la diversidad de circunstancias que engloban a quienes han migrado, con la finalidad de resaltar la existencia de distintas causas de dichos desplazamientos. En una segunda parte, y dentro de la misma óptica, colocaremos una experiencia de vida de una mujer que migró para otro país buscando refugiarse a causa de otro tipo de violencia, ya no de índole socio-político-económico. Esto con el objetivo de mostrar cómo la migración, tal proceso humano y la propia historia, no es estática sino dinámica y transformadora.

\section{Dejando las migajas de pan en el camino}

Entendí la importancia de la comunicación, porque vivía en un mundo silenciado (María Durán).

La Organización Internacional para las Migraciones (OIM) define a un migrante como aquella persona que se desplaza o se ha desplazado a través de una frontera internacional o dentro de un país, fuera de su lugar habitual de residencia, independientemente de su situación jurídica, el carácter voluntario o involuntario del desplazamiento, las causas del 
desplazamiento, la duración de su estancia. ${ }^{2}$ Así, a diferencia del refugiado la decisión del migrante en relación a salir de su lugar de residencia habitual no se condiciona obligatoriamente a problemáticas vinculadas con la violencia y el temor, sino que forma parte de una determinación en fe de mejorar su vida, bien sea a nivel familiar, profesional, emocional, etc.; pero en lo que pareciera un paralelismo debemos tomar en cuenta que un refugiado es un migrante, quien inmigra, aquel que llega a otro país o incluso localidad diferente a la que pertenece con la finalidad de allí establecerse durante un tiempo que no siempre está definido, ni porlas circunstancia ni por la propia persona.

La situación de las migraciones, como ya sabemos, no es un fenómeno contemporáneo, ya desde tiempos pre-históricos existía dicha práctica acrecentándose en la época moderna a partir de la incorporación de criterios ampliados de la posteriormente llamada globalización y sus consecuencias en el ámbito de la salud, alimentación, sistemas de discriminación, procesos económicos y sociales, además de los culturales, vinculados de una u otra manera con la vulnerabilidad de la identidad. Estadísticamente, según datos presentados en el Portal Global de Datos Migratorios, para 2017 el número de migrantes internacionales llegó a un total mundial de 258 millones, superando los datos más recientes provenientes de 2015 cuando se obtuvo un grueso de 244 millones. En dicha investigación se expresa que el $48 \%$ de ese estimado fueron mujeres y 36,1 millones infantes; a esto se agrega 4,4 millones de estudiantes internacionales, lo cual arroja una amplia diversidad. De igual modo es interesante la relación de Asia con una acogida de 31\% de la población de migrantes internacionales, Europa con un 30\%, el continente americano $26 \%$, África $10 \%$ y finalmente Oceanía con el 3\%.3

2 Disponible en: (https://www.un.org/es/sections/issues-depth/migration/index.html) Acceso en: 22 abril 2019.

3 Disponible em: https://www.un.org/es/sections/issues-depth/migration/index.html) Acceso en: 22 abril 2019. 
Figura 1 - Muestra de los 10 principales países de acogida de refugiados para 2015

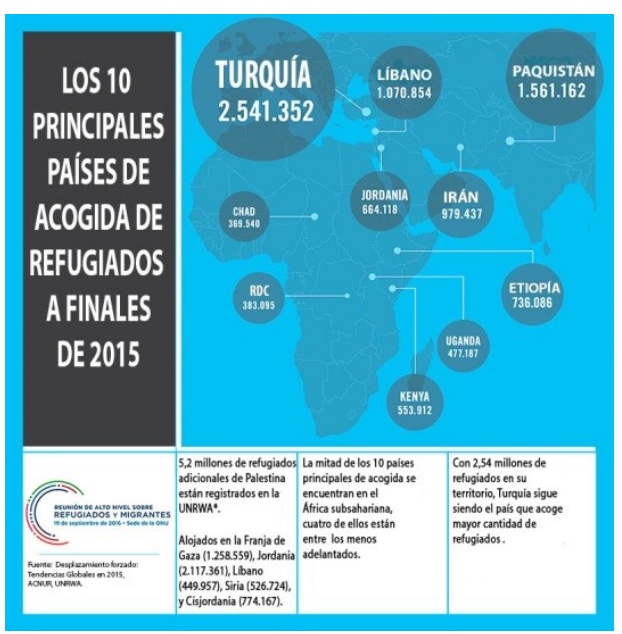

Fuente: $\underline{\text { https://refugeesmigrants.un.org/es/infographics }}$

Frente a lo expuesto en relación a datos migratorios, observamos en la figura anterior estadísticas mundiales en relación a los diez países que para 2015 figuran como principales acogedores de refugiados y migrantes, donde queremos resaltar la cifra de 5,2 millones de palestinos la cual ha ido acrecentando motivada a acciones consecuencias de la ocupación ilegal de sus tierras y territorios. Dentro del mapa también vemos cómo Turquía resalta como lugar de mayor acogida de migrantes en calidad de refugiados, obviamente por estar en una mejor disposición, lo cual es factor para una amplia investigación respecto a los distintos elementos que proporcionan condiciones (económicas y políticas, preponderantemente) para hacer favorable la determinación de albergar grandes contingentes de migraciones, tal como lo explica Aruj (2008) destacando tendencias que impactan a las sociedades para la recepción de migrantes, lógicamente con los consecuentes impactos positivos y negativos, siendo una de ellas

aquella que se vincula con las situaciones de restricción migratoria, las cuales se pueden asumir como políticas strictu sensu, derivadas de proyectos de diferentes estados o como parte de la propia dinámica de acción de un gobierno para evitar flujos migratorios no deseados hacia y desde sus fronteras. Este tipo de acciones se relaciona con los controles migratorios, la discriminación, la exclusión y la persecución, entre otros. Esta situación restrictiva tiende a proponer la selección de migrantes para permitir el acceso a un país, de acuerdo con las necesidades inmediatas que tiene para cubrir puestos de trabajo. (ARUJ, 2008, p. 97) 
Destacamos acá las llamadas "inmigraciones selectivas" que son las aplicadas en países como Noruega, Estados Unidos y Canadá, tal como señala dicho autor en referencia a Oteiza (1986), donde se realiza una vieja técnica de la que fuéramos testigos en una experiencia que tuvimos con una médico ecuatoriano -venezolana quien en la década de 1980 viajó a Estados Unidos con una beca para estudios de especialización y por su excelente desempeño le fue posible "saltar" el rígido sistema burocrático migratorio de dicho país, siendo acreedora de una visa y directo engranaje en un destacado hospital y laboratorio científico, este ejemplo es lo que Oteiza (1986 citado porARUJ, 2008) revela como brain drain, constituyendo de este modo un sistema migratorio bien específico sin cabida en las estadísticas de fuero masivo.

El siglo XXI ha traíd o una serie de transformaciones en la llamada América Meridional, dentro de la que se encuentra la conformación de sistemas de visos socialistas que ha abogado por la conformación de políticas más equitativas buscando una nueva posibilidad de alternativas en el crecimiento sobre todo de las clases no hegemónicas, minoritarias o históricamente invisibilizadas. De manera que se acrecentó el flujo migratorio ya experimentado durante el siglo $\mathrm{XX}$, pero en esta ocasióncon preeminencia dentro de los propios países huyend o de las desigualdades por diversas causas, también la cercanía con la identidad cultural basada principalmente en el idioma común y una culinaria bastante parecida; así con la intensificación de lo que implica la extensión de la globalización, hanido aumentando las crisis económicas y políticas, y por consecuencia sociales, trayendo consigo conflictos en mayor o menor grado, como es el caso de México, Honduras, Nicaragua, Guatemala y Colombia, con fluyentes migraciones por conflictos armados, y más recientemente (agudizado desde 2017) el caso de Venezuela, con unas características álgidas que no tocaremos en este ensayo por requerirse un análisis más profundo imposible de resumir en este número de páginas.

Los cambios en los procesos de acumulación capitalista y la securitización de las fronteras son dos fenómenos que también han afectado considerablemente los movimientos de personas en la región, disminuyendo los flujos en algunos casos, redireccionándolos a otros destinos en otros, incrementando los retornos voluntarios y forzados, y también multiplicandoel tipo de movilidades. (HERRERA; SoRENSEN, 2017, p. 13) 
No obstante, partiendo de lo antes expuesto, podemos decir que ciertamente, la situación de las fronteras es un punto importante en el flujo de migrantes dentro de la propia región y desde allí las condiciones de dichas personas también son un elemento de interés a tomaren cuenta a la hora de analizar dichos procesos, puesto que las variables son múltiples. Así, por ejemplo, conocemos experiencias cercanas de venezolanos que han migrado para Ecuador en una aventura para encontrar una calidad de vida mejor sobre todo porserjóvenes y tener aspiraciones de comprar una casa, tener mayor seguridad ciudadana, entre otros detalles. Otro caso muy distinto es de aquellos que migraron a Brasil a pie por la frontera hacia el estado de Roraima (para el momento de la escritura de este ensayo aún cerrada), sin tener un horizonte cierto sobre su vida y la de su familia, llegando muchas veces a vivir en condiciones iguales o peores de las que estaban huyendo, lo cual a muchos que conocemos los ha llevado a retornar al país de origen. ${ }^{4}$ Caso diferente al de venezolanos que han migrado solicitando refugio a México, Perú, Chile, Argentina, España o el propio Brasil, viajando vía aérea, y luego abriéndose camino a otra oportunidad laboral, etc. O quienes han migrado sin razones de conflictos traumáticos sino porcuestiones laborales u oportunidades de estudios, como el caso de una de las autoras del presente ensayo.

Dentro de todas estas perspectivas sobre migraciones, consideramos interesante la posición epistemológica de Oroza Busutily Puente Márquez (2017) respecto a las migraciones porque la observan como un hecho positivo para el desarrollo de los países de acogida (ya no una fuerte carga económica) 5 y para la configuración de nuevas formas culturales desde la multiculturalidad y la diversidad (también étnica).

Las migraciones conducen inevitablemente a una mayor diversidad étnicay cultural en el interior de los países, transformando las identidades y desdibujando las fronteras tradicionales. En la actualidad, millones de personas en el mundo se trasladan de un país a otro, estableciéndose importantes vínculos de diverso carácter (familiar, social y económico), entre las partes vinculadas en el proceso (OROZA BUSUTIL; PUENTE MARQUEZ, 2017, p. 11).

4 Interesante para ahondar en este fenómeno es la creación por el Estado venezolano del Plan Vuelta a la Patria (en alusión al poema homónimo de Pérez Bonalde) http://mppre.gob.ve/tema/vuelta-ala-patrial Acceso en: 25 abril 2019

5 Se puede ahondar en el tema acessando al link https://www.acnur.org/fileadmin/Documentos/Publicaciones/2012/8951.pdf, y leyendo la sección dedicada a cuánto dinero cuesta tener inmigrantes en ciertos países. 
Las autoras citadas establecen lo que ciertamente ya se fuera construyendo en confluencia de múltiples memorias colectivas (HALBWACHS, 1976) porque cada migrante se traslada con sus propios recuerdos, su propio cúmulo de conocimientos y saberes, es decir, su propio acervo cultural, por ello la idea de la retroalimentación es un campo que no debe dejarse de lado cuando se analizan los procesos migratorios; también huyendo de procesos violentos se puede configurar una nueva visión identitaria, es un poco lo que González Ordosgoitti (1993) Ilama "culturas binacionales" al referirse al flujo migratorio que llegara a Venezuela en las primeras décadas del siglo XX proveniente fundamentalmente de España, Italia y Portugal.

A pesar de que Europa dominó los flujos migratorios del mundo durante siglos-a través de la migración impulsada por la colonización 1500-1800, la migración impulsada por la Revolución industrial 1800-1915 y los desplazamientos intracontinentales masivos ocasionados por las dos guerras mundiales-es solo desde la década de 1960 cuandouna importante afluencia de migrantes procedentes de Asia, África, el Caribe y América Latina convierten a este continente en una región de inmigración y es ese momento que la migración internacional comienza a recibir un interés notable. (HERRERA; SORENSEN, 2017, p. 17-18)

Dicha situación de flujos migratorios desarrollaría en Venezuela una configuración multicultural interesante a la que se sumarían posteriormente inmigrantes provenientes de países árabes, sobre todo Líbano y Turquía, asiáticos como China, y propios de América Meridional, con amplio porcentaje Colombia y Ecuador.

Dentro de todo este panorama podemos inferir que para adentrarnos en el estudio del tema de las migraciones debemos tomar en cuenta que dependemos del momento en que la trayectoria del migrante está siendo analizada (CAIXETA, 2014, p. 14), porque es un hecho, como ya hemos dicho, dinámico y transformador, portanto las variables en relación a razones de migración e incluso lo que puede desembocar posteriormente suelen ser bastante comunes de presentarse. Un ejemplo a analizar es la en ocasiones infundada relación migración-terrorismo, lo cual toma sentido como consecuencia de varios factores, entre ellos: actitudes fuera de la ley por parte de migrantes, refugiados o asilados que luego dejan el país acogedor portand o nueva nacionalidad, lo que los hace receptores y emisores de otras violaciones legales, causando un verdadero inconveniente pues "los migrantes pueden ser expulsados, pero los ciudadanos no" (OIM-ONU., 2018, p. 238); en relación al extremismo 
violento la falta de una definición exacta agrava la situación y, a nuestro parecer, a esto habría que agregar la existencia innegable de sistemas organizados de incrementación de la xenofobia y el rechazo de ciertos sectores por profesar ciertos sistemas de creencias o religiones, como es el caso de la islamofobia, lo que trae cantidad de consecuencias en las que las acciones o atentados violentos extremos le son atribuidas a dichas personas, o más allá su estigmatización, incluso focalizada a infantes y mujeres.

Afortunadamente, lo acotado en el párrafo precedente es solo un detalle de lo que puede ser la vida de cada migrante; dentro de esto es conveniente destacar su condición cultural y el cúmulo de memorias que se desplazan con él, tal como asevera Kristeva (citada por CAIXETA, 2014) el extranjero tiene una biografía muchas veces más sufrida que los nacionales, "Nada como catástrofes ou aventuras (embora tanto uma quanto as outras possam acontecer), simplesmente uma vida onde os atos são acontecimentos, porque implicam escolhas, surpresas, rupturas, adaptações ou estratagemas, sem rotina ou repouso" (CAIXETA, 2014, p. 17) ${ }^{6}$.

Tal como expresa la teoría sobre la memoria colectiva de Halbwachs (1976) respeto a que nadie nunca está solo puesto que tiene sus recuerdos para acompañarle, el extranjero lleva consigo esa parte de suvida que forma su biografía y, curiosamente también parte de la muerte, dentro de lo cual no solo notamos el fallecimiento de seres queridos, sino también la ausencia de quienes quedaron en el país que se ha dejado, junto a los bienes materiales, herencias, que más que un valor económico tienen un valor sentimental, como diría Mario Chagas (2005) espiritual. Para el investigadorpalestino Edward Said (apud CAIXETA, 2014, p. 19)

os exilados "sentem na alma" a amargura de ser apartados de uma cultura que fundamenta toda uma identidade já formada, por isso, vincula o exílio a uma fratura incurável. Ele também aponta que, diferente do que é bastante difundido sobre este conceito, exílio não significa um corte total, uma ruptura que separe o indivíduo do lugar de origem em todos os aspectos. $\mathrm{O}$ exilado tende a viver numa situação intermediária, deslocado, não integrado no novo lugar nem liberto do antigo. Nessa perspectiva, a questão que Said coloca é que "para a maioria dos exilados, a dificuldade não consiste só em ser forçado a viver longe de casa, mas sobretudo, e levando em conta o mundo de hoje, em ter de conviver o tempo todo com a lembrança de que

${ }^{6}$ KRISTEVA, Julia. Estrangeiros para nós mesmos. Tradução de Maria Carlota de Carvalho Gomes. Rio de Janeiro: Rocco, 1994. p. 14. 
ele realmente se encontra no exílio, de que sua casa não está de fato tão distante assim, e de que a circulação habitual do cotidiano da vida contemporânea o mantém num contato permanente, embora torturante e vazio, com o lugar de origem" (SAID, 2005, p. 56).

La memoria desde los recuerdos, en el caso del exiliado (en la calidad migratoria que fuere), como vemos, se plantea desde la perspectiva del afianzamiento a la propia identidad, tal como hemos señalado, lo que lleva a la creación de lugares para llevar a cabo reuniones entre personas de la misma nacionalidad o de cultura cercana (incluyendo el idioma), o a través de redes sociales donde es cada día más usual la existencia de grupos de migrantes que constituyen una suerte de "club" virtual con la finalidad de informarse sobre ciertos acontecimientos del país de origen, compra y venta de alimentos típicos no existentes en el país receptor, intercambio de fotografías de diversos sitios del país de origen, e incluso videos de programas televisivos antiguos, músicas, entre otros, todo lo cual establece lazos memoriales de identidad cultural que, no buscan que el migrante se olvide de su calidad de extranjero, pero si afianzan su existencia a partir de la invención de una especie de realidad paralela que crea la ilusión de no estar tan lejos de casa. Hay que tomar en cuenta, no obstante, que esto varía de acuerdo al "momento" del migrante y su trayectoria histórica, porque si proviene de un país con conflicto bélico o de gran ocupación, como puede ser Palestina, tal creación transitoria de cercanía al hogares más ardua, entrando a escena otros elementos como los simbólicos, por ejemplo la llave de la casa que tal vez ya no existe más, el pañuelo, la comida, etc., es decir, objetos materiales que conforman diversas memorias entre individuos y grupos.

El proceso de migrar es complejo, dinámico, transformadory pleno de elementos vinculados con la memoria y la cultura, esta última frente al sentido de pertenencia; de correspondera algo y de que ese algo sea parte de sí mismo. Por ello no es lícito pensaro creer que se puede hablar de una sola migración con un único motivo, las posibilidades son múltiples, tal como la Historia, el propio humano es quien va escribiendo y diseñando sus caminos en el mundo, por cierto a su vez creado por él, con sus límites, fronteras y distancias. Caminos que se abren a cada paso que damos porque al fin y el cabo somos nosotros quienes limpiamos las malas yerbas que enquistan nuestro destino. Quien migra cobra en la duda la fuerza necesaria para seguir adelante y construir en otras tierras una vida mejor, tal como veremos en la historia de vida que narramos a continuación. 


\section{Hilando los recuerdos de María Durán}

Como parte de esta investigación mostramos la historia de vida de una migrante colombiana que en el primer tercio del sigloXX tuvo necesidad de migrar a Venezuela, como una alternativa de salvaguardar su integridad mental, al ser víctima de Violencia de G énero por parte de su esposo. La narración la construimos desde tres aristas: el testimonio de nuestra protagonista, en el que convergen perspectivas de intersubjetividad derivadas del mundo - de-vida relacional a lo largo de más de nueve décadas de exist encia, de las cuales siete transcurrieron en el espacio territorial de Venezuela, donde migró; los aportes de autores que disertan sobre el mundo de-la-vida, vida cotidiana y fenomenología, que en la discursiva se erigen como hilos conductores del tejido identitario de la migrante $y$, finalmente, nuestra reflexividad a la cual nos incorporamos desde la convergencia de múltiples aristas que sutilmente impregnan la construcción discursiva del ensayo.

Por nuestra condición de ser mujeres en contra de cualquier tipología de violencia de género, hacemos énfasis desde nuestro rol de docentes e investigad oras, en nuestro papel de luchadoras asimismo contra la xenofobia, aspecto que no tiene cabida bajo ninguna circunstancia ética y humanista, aunamos nuestro interés por propiciar el estudio de problemáticas contemporáneas desde la reflexión e interpretación de diversas temporalidades que contribuyan a una amplia comprensión de las mismas y por ende, alternativas de solución pertinentes.

A mediados de la década de los cincuenta del siglo pasado, a una de las investigadoras de este ensayo por tener vínculo consanguíneo con nuestra protagonista, se le facilitó conocer a esta sencilla mujer, quien para entonces residía en una casa de vecindad7, ubicada apenas a 5 cuadras del casco histórico de la ciudad de Caracas, capital de Venezuela. Tenía alquilada allí una habitación con el padre de sus 5 hijos e hijas, con quien vivía en concubinato. De manera que como estudiosas compartimos el interés por investigar sobre las migraciones, consideramos pertinente abordar dicho tema a partirtambién de la historia de vida de María Durán, por emerger una causal de la migración poco visibilizada e investigada pero de gran significatividad en el siglo XXI.

\footnotetext{
7 Pensión de características humildes.
} 
Al adentrarnos en su mundo de vida, le inquirimos sobre las causas que le habían motivado dejar su lugar de origen. Nos comentó que era de Cúcuta, ciudad ubicada al norte de Santander de la República de Colombia. Mientras nos relataba con significativa elocuencia cada detalle, observábamos su mirada firme y penetrante acompañada con el movimiento de sus manos grandes, venosas y afectadas por la artritis. Mirada que por los momentos quedaba fija como hurgando en sus recuerdos para, en profunda retrospección, comenzar a hilar desde sus vivencias oscilantes, marcadas por un antes y un después de haber llegado a Venezuela.

Partimos entonces de lo señalado por Ricoeur (2006) respecto a buscar en los recuerdos e impulsar mirarnos hacia adentro para comentar en un narrarse desde la perspectiva hermenéutica-fenomenológica, y lo asumimos para hilar el tejido del mundo de la vida de María Durán.

Reconocer un recuerdo es reencontrarlo [...] Reencontrarlo teóricamente disponible, si no accesible. Incumbe a la experiencia del reconocimiento remitir a un estado de latencia del recuerdo de la impresión primera cuya imagen debió constituirse al mismo tiempo que la afección originaria [...] El pasado es contemporáneo del presente quefue. (p. 163)

El pasado de María Durán, se vuelve contemporáneo con la elocuencia y fluidez que imprime al narrar el motivo que la impulsó ir a vivir a Venezuela. Destaca con vehemencia que no había sido el aspecto económico, como acontecía con muchos de los paisanos que había conocido en el camino, luego de cruzar la frontera hacia este país. Provenía de un grupo familiar humilde. Su padre Lino Durán, quien siempre tuvo deferencia especial hacia ella, se desempeñaba como albañil y procuró que el alimento diario de la familia nunca faltara. Ella como hija mayor con habilidades para la costura, colaboraba con el aporte económico que devengaba porcoser trajes de toreros. Cuando nos refería este pasaje de la adolescencia, sus ojos asumían un brillo especial y en su rostro de suaves facciones se asomaba con cierta timidez una sonrisa. Nuevamente la nostalgia con una mezcla de emocionalidad acompañaba su mirada y el movimiento azaroso de sus manos, quería como detener ese recuerdo, cargado de tanto significado que se erigía en su presente, anclado con fuerza en su memoria.

La rápida metamorfosis que en María se había generado, nos causó curiosidad y le preguntamos la razón de esa emocionalidad que se entretejía con visos de melancolía. 
Argumentó que en su ciudad de origen era muy relevante la pasión por las fiestas taurinas y aunque nunca asistió como espectadora a ninguna, porque lo que devengaba por su trabajo se constituía en su obligatoria contribución al hogar. Recordaba que centrada en su trabajo de costura, dejaba volar la imaginación y se veía en las gradas disfrutando de las habilidades del torero al encuentro con el animal. Era un desafío que le causaba entusiasmo y se contagiaba con los "vivas" de los espectadores que imaginaba colmaban la Plaza de Toros de Cúcuta. En ese instante, nos confesó igualmente, que en los primeros años de su estadía en Venezuela, antes de vivir en concubinato con Pablo Frías, el padre de sus hijos venezolanos, asiduamente asistía al cine los días libres y las películas de su preferencia, siempre eran donde había escenas de corridas de toros: "para mí, era una manera de sentir que estaba en Colombia y no en Venezuela, además me llevaba a esa etapa feliz de miadolescencia".

Ese juego de temporalidad que comenzamos a percibir al dialogar en María a través de su narración, deja entrever lo oscilante de su mundo interior que, busca reencontrarse con su pasado, con sus recuerdos en tierras extranjeras que le permiten, así lo interpretamos, reconocerse.

[...] El tiempo es la condición formal a priori de todos los fenómenos en general [...] El tiempo es forma pura, no sólo de toda forma de intuición interna, sino de toda intuición externa [...] todas las representaciones, pertenecen siempre, en sí mismas, en cuanto determinaciones del espíritu, al estado interno (RICOUER, 2006, p. 163).

Los múltiples hilos del tejido identitario anclado en los recuerdos de María, en el cual el territorio de origeny la convivencia familiar han dejado huella, fluctúan en la temporalidad de sus pensamientos influenciados por esa distancia territorial que se le hace interminable. Comenzamos, entonces a percibir, que a pesar de los años que tenía de residencia en Venezuela, su país latía permanentemente en ella. Se asomaba un anclaje fuerte que con el paso de los años había encallado la mente y alma de esta orgullosa colombiana en su tierra de procedencia. Nuestra curiosidad fue aumentando al sentir que evadía nuestra interrogante inicial. Al cruzarse con nuestras miradas, se asomó una sonrisa en su rostro y expresó de manera tajante:

yo me vine para Venezuela prácticamente huyendo del que fue mi primer esposo quien desde que yo tenía 17 años cuando me casé hasta los 24 años que me vine para este país, me sometió a un permanente acoso psicológico que me hacía sentir por momentos que me iba a volver 
loca. El nacimiento de mi hija cuando tenía 19 años, me dio fuerza interna para resistir y hasta pensar en la forma de huir de él. No me importaba pasar hambre, trabajo, lo que yo necesitaba y quería para mi hija era pazy no la tenía.

Sorprende y nos conmueve el testimonio. Se trata de acoso psicológico hacia una fémina en el primer tercio del siglo XX, contexto sociohistórico en que se carecía de una legislación favorable hacia la mujer. Asímismo, a través del matrimonio, generalmente en las clases sociales de poco poderadquisitivo, se asumía como un contrato tácito de servidumbre oficial hacia el hombre, por lo que se requería una actitud de sumisión. Su testimonio deja entrever que ante esa injusticia, ella se rebeló, actitud poco común y hasta inconcebible en aquel contexto histórico. Pertinente es aclarar que situaciones de injusticia y maltrato como lo que se interpreta a través de la narración de María, se concibe en el presente, en Venezuela, América Latina y el mundo en general, como Violencia de Género.

La fuerza que imprimió a sus palabras acompañadas de un silencio que respetamos, permitió nuestra meditación sobre esta problemática de la que pocas veces se hace mención, como causal relevante de migración, nos referimos a la violencia psicológica de la que han sido víctimas las féminas de un determinado país. La respuesta a nuestras reflexiones nos la proporcionó la misma María al narrar:

Comenzaba a sentir que era otra mujer. Por momentos no me conocía. Yo que era alegre, echadora de broma y sobre todo, muy habladora, lo que hacía era llorar a escondidas para que él no se burlara de mí. Estaba callada todo el tiempo. Llegué a sentir que como mujer no tenía valor. Recuerdo esos momentos y me parece mentira que los comente como si nada. He tratado precisamente eso. Olvidarme, no recordar esos momentos tristes de mi vida.

Pertinente comentar que para aquella época la Violencia de Género era una problemática silenciada en nuestro continente aunado a la falta de respaldo jurídico para ser abordada y mucho menos solventada, como puede interpretarse a través de la ampliación del testimonio que nos proporciona María con respecto a su señalamiento:

Por un tiempo él, hasta me tuvo lejos del contacto y comunicación con mi familia. Se estaba apoderando de mí una sensación de incertidumbre, de tristeza. Repito que mi hija me generaba una fuerza interior me mantenía en pie. A escondida leía La Biblia y otros libros que el que era mi esposo, ocultaba para que no leyera, para mantenerme todavía más incomunicada. Porque les confieso que en ese tiempo aprendía dialogarcon los autores de los libros que 
leía. Entendíla importancia de la comunicación, porque vivía en un mundo silenciado.

La solidaridad y comprensión ante la Violencia de Género cometida hacia María, nos hace reflexionar sobre las presunciones que se emiten libremente cuando migran mujeres solas. Pocas veces se estudia, se investiga sobre este tipo de situaciones que derivan en tramas de relevante significatividad para percibir las múltiples aristas vinculadas a la migración, más aún, la del género femenino. Al proseguir en su narración, María señala con una profunda carga de dolore impotencia a la vez:

Como estaba dispuesta a no seguir compartiendo mi vida con el padre de mi hija, Consideraba que de seguir a su lado, terminaría enferma mentalmente, me las ingenié y en una oportunidad que me dejó sola en la casa para lograr evadirme de ese lugar. Decidí ir a mi casa y contar del maltrato psicológico al que estaba sometida. No conseguíel apoyo que esperaba. Mis padres aludian que ya yo era una mujer casada y mi deber era estar al lado de mi esposo. Entonces acudí a lo ley a plantear mi problemática. En una primera oportunidad la ley lo favorecía a él. Establecían que el cuidado y protección de nuestra hija corría por cuanta de él, lo que implicaba a la vez, que se le entregaba la custodia de nuestra hija. Midenuncia de acoso psicológico y que prácticamente me había tenido secuestrada, no fue considerada. Prácticamente era como si hablara a la pared. Sentíque cada vez estaba más sola. Como si nadie creyera en mí. Nisiquiera mifamilia.

Hemos de destacar que este cúmulo de injusticias vinculadas a no recibir castigo por emitir Violencia de Género y peor aún, no ser consideradas las acciones de agresión hacia el sexo femenino, con el transcurrir del tiempo, solo a finales del siglo XX e inicio del XXI, es que se da inicio a ciertas preventas para combatir con administración de justicia en mano, aquellas injusticias como las referidas por María, con la finalidad de que no quedaran sin penalización. Oportunas en este aspecto son las reflexiones de Yolanda Jaimes que compartimos:

En 1993 la Conferencia Mundial de Derechos Humanos aprobó la Declaración y Programa de Acción de Viena (Conferencia 57/23), que de manera muy especial y en el plano internacional, llama la atención acerca de los Derechos Humanos de la mujer como parte "inalienable", integrante e indivisible de losDerechos Humanos Universales y pautan que: Ia violencia y todas las formas de acoso y explotación sexuales [...] son incompatibles con la dignidad de la persona humana y deben ser eliminados. Este programa de acción condujo a que en Diciembre de 2003, la Asamblea General de las Naciones Unidas aprobara la Declaración sobre la eliminación de la violencia contra la mujer, definiéndola como todo acto de violencia basado en la pertenencia al sexo femenino que ocasione un daño o 
sufrimiento físico, sexual o psicológico, así como amenazas o coacción y privación arbitraria de la libertad. (2012, p. 78)

Importante aclarar al lector, que en el contexto histórico de la segunda década del siglo XX, al contraer matrimonio, la mujer debía seguir cuál oveja al esposo y, aceptar prácticamente todo lo que en el matrimonio él dispusiera, en especial, en las relaciones maritales. Esta injusticia, motivó a María a acciones más drásticas, con la finalidad de no perder la custodia de su hija o al menos esta responsabilidad la tuvieran sus padres. Narra María que en su desesperación aludió que el padre de su hija no era su esposo. Ante esa declaración, la ley decidió otorgarla custodia de su hija a sus padres, aunque no era justo por serella la madre, aunado que toda la lucha emprendida por denunciar el maltrato psicológico de su esposo hacia ella se centraba en adquirir en total equidad el derecho a protegery estar con su hija alejada de quien la maltrataba psicológicamente, aspecto que incidía igualmente en la salud mental de la niña que para el momento de la querella tenía 4 años.

El reconocimiento de los derechos de la mujer y la tan ansiada equidad de género como ya referimos, se han convertido, afortunadamente, en una razón de lucha y reivindicación, cada vez con más fuerza, como nos lo reitera la autora citada, para que situaciones de minusvalía a los derechos de una madre, como percibimos ocurrió con María, no se susciten más a nivel mundial en el presente siglo.

Hoy en día casi todo el mundo considera la igualdad de género como una necesidad humana. Para que esto llegara, un largo camino recorrió la mujer venezolana, latinoamericana y mundial. Más que igualdad, lo que necesitamos es equidad de género, reconocimiento a conciencia de una justicia de género realmente funcional, efectiva y respetada en todos los ámbitos. Es en el pequeño mundo que nos rodea, donde la mujer debe sentir la equidad que caracteriza la justicia de género. Dentro de su hogar, en el conuco, en el fundo donde trabaja la campesina, en la fábrica donde la obrera cumple su jornada laboral, en las instituciones públicas o privadas donde empleadas, administrativas y profesionales universitarias asumimos responsabilidades de trabajo. (JAIMES, 2012, p.44)

Aunque María no fue beneficiada con toda esta legislación porhaber sido propuestas años posteriores a su proceso de padecimiento de Violencia de Género, saludamos con alegría todo este cuerpo de legislaciones que a nivel mundial han surgido, con el fin de proporcionar real calidad de vida a la mujer sin ningún tipo de distinción. La herida abierta y profunda por este cúmulo de injusticias, en el cual se obviaba su condición de madre y, se 
otorgaba a sus padres la custodia y cuidado de su hija, incidió en ella para tomar la decisión de trasladarse a otro país, a lo que hay que agregar la negativa de otorgar el divorcio el padre de su hija, lo que le hacía pensar que esa situación de acoso psicológico, que se había tornado tormentosa y traumatizante, iba a proseguir. Colocarun distanciamiento territorial, para ella significaba una pertinente solución.

Por otra parte, consideraba María, constituía una acción inmediata y rápida para adquirir la suficiente estabilidad económica y familiar que se constituyera en garante de la futura calidad de vida de su pequeña hija. Al llegar a esta parte de su narración, se asoman nuevamente las lágrimas al conectarse con el recuerdo de la dura y traumatizante separación al expresar:

Es verdad que mis padres serían los que tendrían la custodia de mi hija, pero sentía en ellos el reclamo de haber desafiado a mi esposo, de no haber sido sumisa como correspondía a una esposa, según sus creencias. En otras palabras el ambiente familiar no era nada favorecedor, por cuanto me sentía la causante de un problemay silenciosamente de manera constante mis padres me lo hacían saber. Medité muchas noches antes de tomar la decisión de irme para Venezuela. Cuando sentíque no daría un paso atrás se lo comuniqué a mis padres. Así, como, les referíque sería por un tiempo prudencialy que vendría lo más rápido posible, en la medida de mis posibilidades, a buscar a mi hija. Trabajaría duro en Venezuela para darle todo lo que se merecía. Rogaba que en miausencia le comentaran a mi hija, porque me iba y que la vendría a buscar.

Manteniendo el soporte hermenéutico-fenomenológico, que referimos, al inicio de esta sección del tejido discursivo del ensayo, nos sostuvimos en la teoría de Ricoeur (2006) para darle sentido y comprensión al testimonio de María.

[...] El compromiso es, ante todo, hacia el locutor, es un compromiso de hacer o de dar algo considerado bueno para él. [...] la promesa no tiene sólo un destinatario, sino también un beneficiario. Precisamente por esta cláusula del efecto benéfico, el análisis lingüístico exige la reflexión moral [...]¿De dónde saca sus fuerzas de comprometerse el enunciador de una promesa puntual? [...] la de cumplir con su palabra en cualquier circunstancia, se puede hablar aquí de la promesa de antes de la promesa. Es ella la que da a cada promesa su carácter de compromiso para con [...] Consiste en una voluntad de constancia, de mantenimiento de sí, que pone su sello en una historia de vida enfrentada a la alteración de las circunstancias y a las vicisitudes del corazón. Es una identidad mantenida [...] a despecho de [...] todo lo que inclinarse a trai cionar la palabra dada. Este mantenimiento escapa al rasgo molesto de la obstrucción, cuando reviste la forma de una disposición habitual, modesta y silenciosa, respecto a la palabra dada. Fidelidad (p.165) 
Múltiples fueron los elementos y vicisitudes que desde el momento que cruzó la frontera tuvo de sortear María en esa nueva tierra, que le impidieron cumplir en un tiempo prudencial con aquella promesa, con ese compromiso adquirido con su pequeña hija, pero a la que dialécticamente le fue fiel mientras estuvo María en este plano terrenal. En su mundo interior, su pequeña hija se mantuvo así, niña. Esa niña que nunca se alejó de sus pensamientos, además de constituirse en el anclaje con su lugar de procedencia, Colombia.

María nos refiere al proseguir con su narración, que al llegara Venezuela, el ambiente estaba muy congestionado, confuso y con ciertas alteraciones. Ella había llegado en enero de 1936, época en la que acababa de morir Juan Vicente Gómez ${ }^{8}$. Por esa razón los primeros meses se quedó en San Cristóbal, donde rápidamente fue empleada como doméstica en casa de un Presidente de estado ${ }^{9}$. Con cierto orgullo señala, que muy pronto dejó de desempeñar oficios de limpieza para convertirse en niñera. El cambio de actividad laboral fue motivado cuando los patronos, como ella los denominó, se percataron que ella sabía leer y poseía certificado de salud.

La Venezuela del primer tercio del sigloXX que nos refiere María, era un contexto en el que todavía los efectos socioeconómicos del boom petrolero no habían generado la abrupta transformación de los años venideros, como lo deja entrever en el siguiente testimonio:

Constituía un significativo privilegio de las familias adineradas, de las casas en las cuales trabajé, enviar a sus hijos e hijas a estudiar al extranjero, y en especial a Colombia. Me preguntaba si la escogencia de mi país de origen, se debía que nosotros fuimos Virreinato y Venezuela fue Capitanía General. Recuerdo que en la escuela, cuando yo estaba en Colombia, nos mencionaban que por eso teníamos mejor educación.

Como puede inferirse, en el contexto histórico en el que llega María a Venezuela, todavía los beneficios económicos que se recibían de la renta petrolera no impactaban por igual a todas las clases sociales. La mayoría de la población estaba sumida en un alto analfabetismo y la salud pública era todavía muy precaria, razón por lo cual, cualquier enfermedad, en algunas regiones de Venezuela, se convertía rápidamente en epidemia.

${ }^{8}$ Quien fuera presidente del país que mantuvo su dictadura durante 27 años, solo dejandoel mandato a raíz de su fallecimiento el 17 de diciembre de 1935 , cuando contaba con 78 años de edad.

9 San Cristóbal es la capital del estado Táchira, fronterizo con Colombia. En aquel momento los regentes de los estados eran Ilamados "presidentes". 
María al proseguir en su narración, comenta que ante la facilidad de ser empleada en casa de Presidentes de estado, favoreció el poder ahorrar y, luego de una cierta cantidad que consideró permitía cubrir los gastos de pasaje y tener reservas para distribuir en la familia, volvió a su país para cumplir la promesa que tácitamente le había hecho a su pequeña hija.

Nuevamente en los ojos de María se asomaron las lágrimas. Refirió lo impactante y doloroso que fue para ella al llegara su casaluego de tres años y sentir que era una perfecta desconocida para su hija. Comprendió que su familia no la había apoyado en ese sentido. No le habían dado a entender a su hija, las razones relevantes por las cuales su mamá se había tenido que ir sin poder llevársela. Como había aprendido a no darse por vencida tan rápidamente, afirmó, que en más de tres ocasiones volvió con el mismo propósito de convencer a su hija de vivir con ella en Venezuela. Todas esas veces fueron infructuosas. María no insistió más y, se concretó a enviar dinero para apoyar la crianza de su hija. Nos narró al respecto:

Cuanta tristeza me provocaba el rechazo de mi hija. Yo había trabajado sin descanso para reunir dinero e ir a buscarla y darle una vida sin que le faltara nada, pero sobre todo que tuviera mi amor de madre. Estar sola y tener que sentir en ocasiones que no era muy bien vista al principio en algunas casas que trabajé, por ser colombiana, no había sido fácil. Lo que sucede que realizaba mi trabajo impecable, atendía muy bien a los niños que cuidaba, además que siempre procuré una máxima higiene. Yo sentía que me refugiaba en atenderlos comosifueran mis hijos, para asíno sentir por momentos, ese dolor del rechazo de mi hija, del cual recordaba constantementeal acostarme.

Esta reflexión de María, vinculada a la concepción de la interrelación de la promesa, del compromiso, incide $y$, hasta exige una reflexión moral. Es lo que percibimos e interpretamos en la narración de María, que por momentos piensa que posiblemente ir a otro país y más aún, sin su hija, a pesar de todos los obstáculos que se lo impidieron, no había sido tan acertado. Como sileyera nuestros pensamientos, nos confesó:

En mis recuerdos, en mi memoria, siempre veo a mi hija, no como la vi en mi último viaje que ya era una adolescente, sino como la niña de cuatro años que lloraba cuando me vio con mimaleta en la mano. Nunca he podido disfrutar de una Navidad aquí en Venezuela. Como en mi memoria está como la niña de cuatro años la siento sola, indefensa, sin miamor. No puedo borrar esaimagen de mimente. Como disfrutaruna Navidadasí. Sin querer amargo estasfiestas a mis hijos e hijas venezolanos. Pero es un dolor que está a hí, latente, No he logrado que desaparezca, nisiquiera ahora que se que es madre, qu e no está sola. Pero en mi interior siento que no cumplíla promesa. Yo siempre lo que me 
propongo lo he logrado. La gente que me conoce, dice que soy perseverante. Perosencillamente le fallé a mi hija Aracelis.

Nos causa conmoción este testimonio y sentimos significativa interconexión con el señalamiento de Ricover (2006): "[...] la relación que establecemos entre la memoria y la promesa, hace eco en un sentido [...] entre el perdón y la promesa, en la medida en que el perdón hace de la memoria inquieta una memoria apaciguada, una memoria feliz." (p.170). Percibimos que María perdona a su hija al conservarla en su mente como la niña de cuatro años, indefensa y sin la claridad propia de la niñez. El conflicto interno que no ha superado, es que ella no se perdonay, por ello, en algunas ocasiones, su memoria no es feliz.

Nos sorprende al proseguirsu narración:

Decidí venirme a vivir a Caracas. Necesitaba sentir una mayor distancia territorial de mi hija. Recuerdo que en uno de los tantos libros que leí, cuando el padre de mi hija me tenía secuestrada, el autor decía: "yo tengo el hábito irreflexible de huir del lugar donde un grandolor ha herido mi corazón, comosi huyendo del lugar, huyera de mi propio dolor". Al poco tiempo de llegar a Caracas, conocía Pablo, con quien he vivido en concubinato por no haberme podido divorciar. No me ha proporcionado lujo. Como ustedes pueden observar, vivimos en esta casa de vecindad, en uncuarto grande los siete. Mis cinco hijos, él yyo. No nos falta comida gracias a Dios, porque Pablo trabaja en el mercado vendiendo limones $y$, realiza intercambio con los otros vendedores del mercado. Por ello cada vez que llega al mediodía viene con abundante comida.

Las vivencias y experiencias cargadas de sentidos, que emergen de la narración de María, nos impulsan adentrarnos en la esencia del diálogo que hemos logrado establecer, siguiendo los postulados de Schutz (1973, apud AZPÚRUA, 2004): "...el mundo social puede ser descrito tal y como es espontáneamente encontrado y descrito por aquellos que en este viven". (p.70). De allí que María considere pertinente profundizar en su relato y señala:

Porno poseer en ese tiemponevera, me veía en la necesidad de cocinar todo el mismo día. Como resultaba abundante, lvego de comer nosotros siete, el resto de la comida la repartía entre unos familiares de Pablo, que trabajaban cerca de la casa de vecindad y entre algunos de los hombres solos, que no tenían familia aquíen Venezuela y, también estaban alquilados en la misma casa de vecindad. Podría decirte que diariamente comían entre 15 a 20 personas. Tu sabes que es grato dar y compartir, así era en mi casa en Colombia; además, prácticamente esa casa de vecindad era una casa de migrantes. Exceptuando a Pablo, mis hijos y unos tres hombres orientales que trabajaban en actividades de construcción, todos los demás que estaban allí alquilados eran migrantes, empezando por los dueños que eran gallegos, comentaban se habían venido a Venezuela a raíz de la guerra civil española. 
Como nos pareció de interés esta información, le solicitamos comentara un poco más sobre esta vivencia, lo cual realizó con mucho agrado porla emocionalidad que imprimió a su narración:

Los que eran de las Islas Canarias, referían igual, que los había afectado la guerra civil española y habían decidido venir a este país. Los italianos afirmaban que muchos les habían ofrecido previamente contratos de trabajo en la construcción durante la dictadura de Marcos Pérez Jiménez ${ }^{10}$. Algunos de ellos eran contratistas especializados en la construcción de puentes, avenidos y autopistas. Precisamente era lo que más habian realizado aquí en Caracas. Se habían traído familiares en esta gran aventura, por ello muchas veces los trabajos donde los había contratado el gobierno, había sido casi una empresa familiar. Luego decidieron quedarse aquí porque se casaron con venezolanas. Los que vivían ahora en la casa de vecindad tenían poco tiempo aquí en Venezuela y trabajaban en las empresas que habían creado sus familiares. No sé porque se vinieron los portugueses que también estaban a llíalquilados y, los árabes solo recuerdo que iban por los barrios a vender ropa interior, lencería en unas maletas grandotas. Esa información la tengo porque había cierta confianza, porque era yo la que les lavaba la ropa. Con el dinero que recibía era que yo quien mantenía los estudios de mis hijos. Lo que me daba Pablo erapara comery pagar el alquiler de la habitación.

Estos recuerdos narrados por María, nos ha permitido conocer la convivencia en otro contexto y tiempo histórico de un determinado grupo de migrantes de gran diversidad culturaly, porende, diferentes costumbres y gastronomía. La curiosidad nos impulsó que nos hablara al respecto

Como les señalé los dueños de la casa devecindad erangallegos, y por serellos migrantes, creo favorecían en algo la convivencia del resto de los que allí vivíamos. Había un espacio grande que acondicionaron como la cocina donde en las noches en sus respectivas cocinas de Kerosen de una o dos hornillas, cocinaban sus alimentos. Ahíveías: caldo gallego, potajes que era una especie de minestrón que hacían los canarios. Los italianos indudablemente sus espagueti. Por cierto se convirtió en una costumbre mía de cocinarlos todas las noches para mis hijos. Los árabes realizaban muchas comidas con carne molida, perejil y otras hierbas. Aunque ellos comentabanque al mediodía, los que trabajaban en la construcción, comían era pan con queso y jamón, porque no podían comer pesado para que no les diera sueño y así evitar cualquier accidente. Losfines de semana los dueños permitían colocar música. Cuando colocaban los pasodobles me acordaba de mis toros. Tengo que decirles que por ser la que les lavaba la ropa a casi todos ellos me tenían respeto y consideración. Me decían que me admiraban porque mis hijos siempre estaban

${ }^{10}$ Férrea dictadura militar que vivió Venezuela entre 1953-1958. 
limpios y eran respetuosos. Les confieso que con mis hijos me esmeré que comprendieran que ser humildes, comoéramos, no significaba andarsucio. La habitación la mantuve siempre impecable para que ellos en el futuro tuvieran hábitos de limpieza. Como ustedes podrán observar esta vida no ha sido nada fácil. Perolvego de la traumatizante separación de mi hija Aracelis, al salir de Colombia, me juré a mímisma, que si volvía a tener hijos no me separaría de ellos y en las buenas yen las malas siempre estaríamos juntos.

Sobre esto develamos de Schutz (1973, apud AZPÚRUA, 2004):

El mundo del sentido común se encuentra tipificado en categorías de significados que permiten reconocer los nuevos fenómenos e incorporarlos a la conciencia del sujeto [...] No existe una única interpretación de las vivencias, sino que, varían según la perspectiva desde, la que sean interpretadas, esto es, según el Aquí y Ahora que experimenta el sujeto. (p.13)

Bajo este mismo sendero reflexivo, nos apoyamos en Dilthey (apud HIDALGO; LÓPEZ, 2015), cuando asevera que la comprensión de las acciones requiere reconstruir el contexto y, a la vez, revivir dicho contenido que es, sin duda, de índole espiritual. Los señalamientos de Dilthey, constituyen en sí, gran parte del proceso hermenéuticofenomenológico que a partir de la interacción subjetiva e intersubjetiva, emerge desde el testimonio y narración de María. Podemos percibir un micro mundo sociocultural presente de manera oscilante en correspondencia a los significados, sentidos y creencias, que interpretamos en el mundo de vida y experiencias de María. Reflejo que observamos se proyecta en la casa de vecindad con significativa presencia migratoria y convergencia de una acentuada diversidad cultural, siguiendo el curso discursivo de la narración de la entrevistada.

Casi finalizando nuestro ameno diálogo con esta gran luchadora, le comentamos que era común que cuando alguien migra, se les requiere la obtención de permiso, carnet o certificado para poder laborary para que su estadía tenga legalidad. Le preguntamos cómo había hecho en su caso y, cuales exigencias le habían solicitado, en el tiempo histórico que llegó a Venezuela:

Recuerdan quecomenté la ventaja de saber leer y tener micertificado de salud. Lo de leer fue una ventaja porque la mayoría de las personas humildes como yo no sabían leer. Certificado de saludera primordial, en especialsiuno trabajaba como doméstica y más en mi caso que fui niñera. Luego cuando llegó a la 
presidencia Isaías Medina Angarita ${ }^{11}$ se inició el proceso de cedulación. Por cierto empezaron por los migrantes y en orden alfabético, será por eso que me correspondió el No. 2.306, por la c de Colombia. Durante un largo tiempo aparecía en micédula transeúntey luego de unos 5 años aproximadamente me dieron la residencia, que garantizaba mi total estabilidad en este país.

Tuvimos curiosidad por saber si ella era nacionalizada y nos respondió de esta manera

Nunca quise nacionalizarme. A pesar del agradecimiento que he sentido hacia este país y que puedo decir con total sinceridad, hay muchas ventajas parasu población, no hay tanta separación social como en mipaís. Aquíobservo que al lado de una quinta puede haber una casa humilde. Jamás verás eso en mi país. Pienso que más que nacionalizarme le he dado a este país cinco venezolanos, Qué mejor muestra de agradecimiento para este país al cual llegué en el momento más triste de mi vida. Mi país lo he tenido en mente y corazón. Saben que nunca dejo de leer el periódico y busco siempre las noticias que hablen de Colombia. Siempre fui una admiradora de Eliezer Gaitán. Realmente todo hubiese sido distinto si no matan a Gaitán. Yo me siento orgullosa de ser colombiana.

Sencillamente María nos sorprende cada vez más. Realmente contagia observar su mirada. Como se transforma y brillan sus ojos al hablar de su país de origen. Su patria no ha salido de su mente. Muchos años después de este diálogo tan ameno con María, tuvimos noticias de su muerte a la edad de noventa y ocho años. Sin lugar a dudas una larg a vida. Por el vínculo consanguíneo de una de las investigadoras de este ensayo, nos enteramos de un significativo acontecimiento al día siguiente de su entierro. La más pequeña de las hijas del concubinato con Pablo, al despedirse de su hermana Aracelis (aquella niña de cuatro años que María tuvo que dejar en Colombia cuando se vino para Venezuela) quien había venido con uno de sus hijos al entierro de su mamá, tuvo la significativa iniciativa de reivindicar a esa mujer que pasó portantas adversidades, que fue siempre perseverante y según sus hijos, una madre irrepetible. En coherencia con este deseo, elaboró una carta para su hermana Aracelis como si la hubiese escrito María y, a través de este texto, narraba con todo lujo de detalles, las múltiples circunstancias que habían motivado que María se fuese para Venezuela en 1936.

Bajo el impacto de esta acción, interpretamos que el sendero que correspondió transitar en este plano terrenal a María, no podía habertenido mejor cierre. Ser reivindicada ante el corazón de esa niña, a quien le había prometido ir a buscar y como no pudo concretar

\footnotetext{
${ }^{11}$ Presidente de Venezuela desde 1941 a 1945.
} 
esa promesa, se mantuvo como una deuda incumplida, en el alma y mente de María Durán, la migrante colombiana que llegó a Venezuela un 26 de enero de 1936.

\section{A manera de cierre. Las complejas aristas de la migración}

A través de esa relevante y simbólica vida cotidiana de María Durán, presentamos la relación dialógica, subjetiva e intersubjetiva, impregnada de múltiples aristas que desde la interrelación de la fenomenología y hermenéutica emerge y, sobre esa discursividad poder interpretar la migración, singeneralizar.

Bolivar y Domingo (2006), se incorporan a nuestras reflexiones señalando: "El juego de subjetividades que se producen en un relato biográfico, basado en un diálogo consigo mismo y con el oyente en busca de una verdad consensuada, es un proceso dialógico, privilegiado de construcción de comprensión y significado"(p.4) Indudablemente el diálogo abierto, sin trabas que sostuvimos con María, en el presente se ha desbordado en América Latina un intenso proceso de migración en especial de mujeres. Cuántas tendrán relatos de vida similares a las de María Durán, encontrándose silenciadas, invisibilizadas. Posiblemente investigarlas seguiría ampliando la complejidad de este histórico proceso que en la contemporaneidad afecta con cierta particularidad a los países del continente americano y más allá el mundial.

El complejo mundo -de -vida que constituye el tejido identitario de quien tiene que migrar, va más allá de causas económicas. Donde la imagen, la huella del país de origen, los afectos, la espiritualidad, están anclado en la memoria, en el recuerdo. Se genera así una sin igual resistencia, al olvido de quien es, de quien ha sido nacional y aún lo es en su fuero interior.

Los procesos migratorios son tan complejos como las propias sociedades que los han venido construyendo a lo largo del tiempo, sin embargo, dentro de toda esta realidad y más allá de las estadísticas está el hecho de la multiplicidad, en varios sentidos: aquella que se crea a partir de la existencia de diversas culturas en un mismo territorio; la ética (a partir de, incluso, conexiones románticas entre congéneres); la lingüística (con la incorporación de nuevas lenguas construidas con inclusión de idioma nacional del país receptor y palabras de idiomas extranjeros), y así una serie interminable de aportes relacionados con memorias y olvidos. Pero dentro de todo esto cabe destacarprincipalmente que nos podemos hablarde una sola migración o una sola situación de refugio, mirando con una única óptica, pues 
también son múltiples los factores que lleva a individualidades o grupos a intentar re comenzar en otras tierras.

Desde la experiencia narrada por María Durán, queremos abrir una invitación, un diálogo nuevo y contemporáneo donde se analice el fenómeno de la migración desde otra perspectiva, más allá de lo meramente sustancial político, económico y social, dando paso a la vida de la mujer que, sola decide huir de la Violencia de Género y gritar al mundo su capacidad de seguiradelante con dignidad y libertad.

\section{REFERENCIAS}

AUGÉ, Marc. Los "nolugares", espacios del anonimato. Una antropología sobre la modernidad. Barcelona: Gedisa, 1993.

ARUJ, Roberto $S$. Causas, consecuencias, efectos e impacto de las migraciones en Latinoamérica. Pap. poblac, Toluca, v. 14, n. 55, p. 95-116, marzo 2008. Disponible en http://www.scielo.org.mx/scielo.php?script=sci arttext\&pid=S140574252008000100005\&lng=es\&nrm=iso . Accedido en 24 abr. 2019.

AZPURUA, Fernando. El interaccionismo simbólico y la fenomenología social. Sus principales contribucionesa la etnosociología. In: Revista Arbitraje, v. 2, n.3, p.63-74. APUNESR.

BOLIVAR, Antonioy DOMINGO, Jesús. La investigación biográfica y narrativa en Iberoamérica. Campo de desarrollo y estado actual. Disponible en Forum Qualitative Social. Researchgate.net, v. 1, n. 4, 2006. Acceso en 24 abr. 2019.

CAIXETA, Sheila Couto. Memória e identidade em narrativas de migrantes : A chave de casa de Tatiana Salem Levy e Azul-corvode Adriana Lisboa. 2014. 75 f. Dissertação (Mestrado em Literatura)-Universidade de Brasília, Brasília, 2014.

CHAGAS, Mário. Casas e portas da memória e do patrimônio. In: GONDAR, J. y DODEBEi, V. (Org.). O que é a memória? Rio de Janeiro: Contra Capa Livraria, 2005. p. 115-132.

GONZÁLEZ ORDOSGOITTI, Enrique Ali.(1993). Lo bicultural-binacional en expansión. In: Daniel Mato (Coord.). Diversidad cultural y construcción de identidades. Caracas: Fondo Editorial Tropykos CEAP-FACES-UCV. p. 35-73.

HALBWACHS, Maurice. Les cadres sociaux de la mémoire. Mouton: Paris, 1976.

HERRERA, Gioconda; SORENSEN, Ninna Nyberg. Migraciones internacionales en América Latina: miradas críticas a la producción de un campo de conocimientos. Presentación del dossier. Íconos, Quito, n. 58, p. 11-36, Agos. 2017. Disponibleen: http://scielo.senescyt.gob.ec/scielo.php?script=sci arttext\&pid=S1390$12492017000100011 \& \operatorname{lng}=e n \& n r m=i s o$. Acceso en: 24 abril 2019. http://dx.doi.org/10.17141/iconos.58.2017.2695. 
HIDALGO, Yaremis. D. T.; LÓPEZ CRUZ, Yenisey. L. La hermenéutica en el pensamiento de Wilhelm Dilthey. Griot : Revista de Filosofia, v. 11, n. 1, p. 324-341, 2015. Disponible en:

https://www3.ufrb.edu.br/seer/index.php/griot/article/view/625 DOI:

https://doi.org/10.31977/grirfi.v11i1.625 Acceso en: 2 may 2019.

JAIMES, Yolanda. Ideas y propuestas acerca de la justicia de género. Caracas: Serie Eventos, n. 43. Tribunal Supremo de Justicia. Fundación Gaceta Forense, 2012.

OIM-ONU. Informe sobre las migraciones en el mundo 2018. Disponible en:

https://publications.iom.int/system/files/pdf/wmr 2018 sp.pdf Accesoen 24 abr. 2019.

OROZA BUSUTIL, Rebeca; PUENTE MARQUEZ, Yoannis. Migracióny comunicación: su relación en el actual mundo globalizado. Rev Nov Pob, La Habana, v. 13, n. 25, p. 10-16, jun. 2017.

Disponible en http://scielo.sld.cu/scielo.php?script=sci arttext\&pid=S1817-

40782017000100002\&lng=es\&nrm=ison Acceso en 24 abr. 2019.

RICOUER, Paul. Caminos del Reconocimiento. Tres estudios. Traducción de Agustín Neira. Paris:

Fondo de Cultura Económica, 2006.

\section{Dados das autoras}

\section{Jenny González Muñoz}

Pós doutoranda em História - Universidade de Passo Fundo (PNPD - Capes). Doutora em Cultura e Arte para América Latina e do Caribe - Universidad Pedagógica Libertador (Venezuela) - Mestra em Memória Social e Patrimônio Cultural - Universidade Federal de Pelotas (Bolsa em Demanda Social - Capes). Licenciada em Artes - universidad Central de Venezuela. Docente pesquisadora com énfasis na cultura material desde os processos antropológicos, tratados das religiôes, mitología e rituais das culturas indígenas da América, tratmentos da morte nas diversas culturas. É editora. Foi cordenadora do Doutorado em Patrimônio Cultural da Universidad Latinoamericana y del caribe, Caracas, Venezuela, e professora a nvel universitario nas áreas da Ciências Sociais. Tem vários livros publicados, entre eles um que aborda o vudú haitiano. Também tem vários artigos publicados e tem feito palestras e conferencias a nivel nacional e internacional. E-mail: jenny.planificacion@gmail.com

\section{Noemí Frías Durán}

Doctora en Cultura y Arte para América Latina y El Caribe (Universidad Pedagógica Experimental Libertador Instituto Pedagógico de Caracas, Venezuela) Magister en Enseñanza de la Historia (UPEL -IPC) Coordinadora del Doctorado en Cultura y Arte para América Latina y El Caribe y del Centro de Investigación Cultural "Mariano Picón Salas" (CIMAPISA) del Instituto Pedagógico de Caracas..Docente en Historia, Ciencias Sociales, Procesos de la Cultura en: Identidades Sociales y Comunitarias / Cultura y Turismo/ Investigación Cualitativa.. Entre sus publicaciones destaca: "La Cultura Popular y la Enseñanza de la Historia de Venezuela"; "Aproximación al diagnóstico geohistórico de la Parroquia La Pastora"; "Creencias, significados y sentidos sobre la praxis docente crítica. Un estudio Autobiográfico". Tiene una amplia trayectoria en el ámbito de la investigación con énfasis en la cultura inmaterial. Email: noemifrias@hotmail.com 